\title{
Contemporary psychology and women: A gender analysis of the scientific production
}

\author{
Julio González-Álvarez ${ }^{1}$ and Teresa Cervera-Crespo ${ }^{2}$ \\ ${ }^{1}$ Department of Basic and Clinical Psychology and Psychobiology, University Jaume I of \\ Castellón, Castellón de la Plana, Spain \\ ${ }^{2}$ Department of Basic Psychology, University of Valencia, Valencia, Spain
}

\begin{abstract}
$D$ espite important advances made in recent decades, women are still underrepresented in science (less than $30 \%$ of authorships). This study presents a bibliometric analysis of all the Psychology articles published in 2009 included in the Web of Science database (Thomson Reuters) in order to examine the contribution of women in contemporary Psychology, their pattern of research collaboration, the scientific content and the scientific impact from a gender perspective. From a total of 90,067 authorships, gender could be identified in 74,413 (82.6\%) of them, being 40,782 (54.8\%) male authorships and 33,631 (45.2\%) female authorships. These data corresponded to 24,477 (49.9\%) individual men and 24,553 (50.1\%) women, respectively. Therefore, Psychology presents gender parity in the number of authors, and a gender asymmetry in the number of authorships that it is much lower than in science in general and other specific scientific fields. In relative terms, women tend to be concentrated in the first position of the authorship by-line and much less in the last (senior) position. This double pattern suggests that age probably plays a role in (partly) explaining the slight gender disparity of authorships.
\end{abstract}

Keywords: Psychology; Gender; Women; Scientific production; Collaboration patterns; Scientific impact.

Despite progress in recent decades, women are still underrepresented in science. Some large-scale analyses reveal that global gender disparities persist in different scientific fields. Thus, Larivière, Ni, Gingras, Cronin, and Sugimoto (2013) reported a worldwide bibliometric analysis of more than 5 million articles, including more than 27 million authorships, and they found that globally women represent fewer than $30 \%$ of scientific authorships. West, Jacquet, King, Correll, and Bergstrom (2013) analysed more than 8 million scientific documents from the JSTOR corpus, and again observed important gender inequities in the research production.

In addition to overall large-scale studies, recent work has performed gender analyses in specific disciplines, such as Nanoscience and nanotechnology (Sotudeh \& Khoshian, 2014), Computing research (Cavero, Vela, Cáceres, Cuesta, \& Sierra-Alonso, 2015), Software engineering (Vela, Cáceres, \& Cavero, 2012), Materials science (Mauleón \& Bordon, 2006), Medical literature (Jagsi et al., 2006) or Neuroscience (González-Alvarez \& Cervera-Crespo, 2017).
Bibliometric studies in Psychology are abundant (e.g., Cumming, Siddle, \& Hyslop, 1997; González-Alvarez \& Palomar-García, 2014; Quayle \& Greer, 2014), but gender analyses within the psychological field are scarce, not recent enough or confined to a specific geographical area (Boice, Shaughnessy, \& Pecker, 1985; D’ Amico, Vermigli, \& Canetto, 2011; Guyer \& Fidell, 1973; Malouff, Schutte, \& Priest, 2010). For example, Barrios, Villarroya, and Borrego (2013) recently analysed a sample of 522 psychology papers/reviews published in 2007 and included in the Thomson ISI Web of Science (WoS), using the criterion that Spain had to appear in the affiliation of the corresponding author.

Beyond a specific country, we were interested in examining women's participation in worldwide contemporary psychology on a large scale. To accomplish this objective, this paper reports on a bibliometric study of all the Psychology articles published in 2009 and included in the Thomson ISI WoS, in order to analyse the scientific production, the pattern of research collaboration, the content and the scientific impact from a gender perspective.

Correspondence should be addressed to Julio González-Álvarez, Departamento de Psicología Básica, Clínica y Psicobiología, Av. Vicent Sos Baynat, s/n, University Jaume I, 12071 Castellón de la Plana, Spain. (E-mail: gonzalez@psb.uji.es).

This work was supported by the Spanish Ministry of Economy and Competitiveness (Research Grant FFI2014-54088-P). The authors would like to thank three anonymous reviewers for their valuable comments and suggestions that helped to improve this work. 


\section{METHOD}

\section{Database}

This study was based on Thomson Reuters' WoS database, specifically the Social Sciences Citation Index (SSCI). Unfortunately, other scientific database, such as Scopus, are unable to automatically provide the authors' full names from a set of records. All the articles published in SSCI during 2009 were selected (year published $=2009$; document type $=$ articles), and subsequently the records were refined to obtain the articles belonging to all the Web of Science Categories (WC) related to Psychology (see Table 1). Consequently, our sample was the universe of all the Psychology articles published in 2009 and included in the SSCI: 27,157 articles signed by 90,067 authorships.

The records were extracted in text format and preprocessed through the BibExcel software (Persson, Danell, \& Wiborg-Schneider, 2009), in order to perform the subsequent bibliometric analyses with the BIbExcel and Microsoft Excel 2010 programs. We chose that year (2009) because it is recent enough to represent a broad sample of the scientific production within contemporary psychology and, at the same time, far enough in the past to allow us to study the citations received by the papers published that year.

\section{Gender identification of authors}

The WoS database does not provide information about the authors' gender. However, in 2008 the WoS began to include the authors' full names (field tag AF: Author Full Name), although a small proportion of records still display only the authors' initials. After a preprocess of normalisation that eliminated initials accompanying given names and replaced hyphens with spaces, all the authors' first names were matched through GenderChecker, a database that included 97,500 worldwide names classified as male, female or unisex (obtained from http://genderchecker.com/; an updated version includes 102,142 names). This database was tested in the validation section (see below), and recently it is used in research (e.g., Carnahan, Kryscynski, \& Olson, 2016; Mansour et al., 2012; Yun et al., 2015) and, according to the website, by the UN Refugee Agency. In order to increase the number of observations, we followed Larivière et al.'s (2013) procedure, and the names classified as unisex by GenderChecker were subsequently matched with the 1990 US Census, which presents lists of given names and their frequencies associated with males and females from the US population. When a name classified as unisex presented a rate above $90 \%$ versus $10 \%$ associated with a specific gender in the US Census, the name was finally classified as belonging to that gender.
For example, "Aaron" appeared in the US Census 7209 times linked to men and 64 times linked to women $(99.1 \%$ vs. $0.9 \%$ ); therefore, it was considered a male name. Conversely, the name "Carmen" accounted for 6210 women and 330 men (95\% vs. 5\%); consequently, it was classified as a female name.

\section{Procedure}

After identifying the gender of the authorships of each publication, each variable studied was extracted using the BibExcel program (Persson et al., 2009). This software is a toolbox for bibliometricians that creates a file in which the values of an extracted variable are associated with each individual paper (identified with a number). Finally, the values of all the variables studied were combined and entered in a master Excel database to perform the bibliometric analyses. Variables studied, statistical analysis, and validation study are provided in Appendix S1, Supporting Information.

\section{RESULTS}

\section{Authorships and authors}

A total of 27,157 Psychology articles published in 2009 were obtained from the SSCI database of WoS. Table 1 presents the number of articles and the number of authorships that appear in those articles, distributed by Web of Science Categories (WC). Authorships with known gender (male or female; third column) have been separated by gender (following columns). Data are sorted by female-authorship percentages in descending order (categories will be discussed in the Content section). In all, the articles were signed by 90,067 authorships (see total in Table 1), yielding an average of 3.32 authorships/paper. After excluding the authorships with only initials, unisex names or given names that did not match the GenderChecker database, we obtained 74,413 $(82.6 \%)$ items with known gender (male, female) belonging to 25,684 papers $(94.6 \%$ of total; henceforth, the percentages of female or male authorships will always refer to the known-gender total). Importantly, the total number of authorships with known gender included $40,782(54.8 \%)$ authorships corresponding to men and $33,631(45.2 \%)$ corresponding to women. Although the percentage of female authorships is close to parity $(50 \%)$, the gender inequality was significant. That is, applying the chi-square test, the difference between male and female authorships was statistically significant, $\chi^{2}(d f=1)=687.20 ; p<.0001$. Nevertheless, Psychology presents a much lower gender imbalance than science in general. Thus, Sugimoto and colleagues (Larivière et al., 2013) examined more than 27 million authorships worldwide across all scientific disciplines, finding that 
TABLE 1

Number of articles, authorships and percentages of male and female authorships in Psychology (Web of Science, WoS, 2009) distributed by Web of Science Categories (WC)

\begin{tabular}{|c|c|c|c|c|c|c|c|}
\hline Web of Science Categories (WC) & Articles & Authorships & Known gender & Male authorships & $\%$ & Female authorships & $\%$ \\
\hline Psychology, Developmental & 3089 & 11,997 & 9911 & 4259 & 43.0 & 5652 & 57.0 \\
\hline Psychology, Educational & 1355 & 3909 & 3221 & 1488 & 46.2 & 1733 & 53.8 \\
\hline Psychology, Clinical & 5192 & 20,638 & 17,225 & 9208 & 53.5 & 8017 & 46.5 \\
\hline Psychology, Multidisciplinary & 5655 & 17,641 & 14,438 & 7824 & 54.2 & 6614 & 45.8 \\
\hline Psychology, Social & 2873 & 8453 & 7034 & 3931 & 55.9 & 3103 & 44.1 \\
\hline Psychology, Psychoanalysis & 505 & 754 & 695 & 419 & 60.3 & 276 & 39.7 \\
\hline Psychology, Biological & 1212 & 4839 & 3898 & 2364 & 60.6 & 1534 & 39.4 \\
\hline Psychology, Applied & 2676 & 7828 & 6347 & 3884 & 61.2 & 2463 & 38.8 \\
\hline Psychology, Experimental & 4068 & 12,616 & 10,552 & 6595 & 62.5 & 3957 & 37.5 \\
\hline Psychology, Mathematical & 532 & 1392 & 1092 & 810 & 74.2 & 282 & 25.8 \\
\hline Total & 27,157 & 90,067 & 74,413 & 40,782 & 54.8 & 33,631 & 45.2 \\
\hline
\end{tabular}

Note: Data are sorted by female-authorship percentages in descending order.

women accounted for fewer than $30 \%$ of them. West et al. (2013) analysed a subsample of 1.8 million science and humanities papers extracted from the JSTOR corpus, and they found that only $21.9 \%$ were female authorships.

Logically, authorships are not the same as individuals (authors) because an individual can publish several papers. Our database includes authors' full names and also surnames and affiliations. We assumed that two or more records (authorships) with the same name and surname belonged to the same individual (author). If necessary, the affiliation was consulted. This way, the 40,782 male authorships corresponded to 24,477 (49.9\%) different individuals (authors), yielding a mean productivity of 1.67 articles/author. In the case of women, the 33,631 female authorships corresponded to 24,553 $(50.1 \%)$ individuals, yielding a mean productivity of 1.37 articles/author. For each author (individual), we obtained the number of papers published by that author, and then all the authors were separated by gender (men, women) in order to carry out a between-subjects one-way analysis of variance (ANOVA). The analysis showed that the difference between male and female productivity was significant, although the effect size was small, $F(1$, $49,028)=703.92, M S E=1.53, p<.0001, \eta_{p}^{2}=.014$.

The geographical location of each author's institution was identified by means of the $\mathrm{C} 1$ field. Table 2 presents the distribution of the authorships according to their gender and country, sorted by the total number of authorships in descending order. The results for the main scientific output country, the United States of America (USA), show that $46.5 \%$ were female authorships. To obtain the psychology production of the European Union (EU), we added the data from all the EU countries (EU-28) and found that $42.8 \%$ were female authorships, which is $3.7 \%$ lower than the US percentage. This difference was small, but significant: $\chi^{2}(1)=76.26 ; p<.001$; Cramer's $V=.036$. It is worth mentioning that countries such as Finland, Italy, Brazil, Turkey or South Africa display percentages of female authorships above $50 \%$. At the other extreme, Japan stands out for its low female participation in psychology publications $(29.8 \%)$, a result also found in other bibliometric studies on scientific production (Larivière et al., 2013).

\section{Collaboration}

In recent decades, collaboration among researchers has increased considerably in science in general and within the psychological field (Kliegl \& Bates, 2011). The sample of 27,157 psychology articles analysed in this study were signed, on average, by 3.32 authors per paper, considering all authorships (known and unknown gender). After selecting the authorships with known gender, the collaboration index was 1.50 authorships/paper for men, whereas for women it was 1.34 authorships/paper. This difference is logical because there are fewer female authorships to be divided by the same denominator.

Table 3 shows the number of authorships/article separated by gender. The calculation procedure was the following. First, the papers with a single authorship were selected from the whole sample, and subsequently the percentages of male and female authorships in this subsample were calculated. Next, the papers with two, three or more authorships were successively selected, and again the percentages of male and female authorships were computed for each subsample. There is clearly a low rate of women among the single-author papers (35.9\%), compared to the overall percentage of female authorship $(45.2 \%)$. It is worth noting that there is an increase in the percentage of women's participation as the number of contributing authors in each paper increases, reaching $49.2 \%$ of female authorship in articles written by more than ten authors. In fact, the Pearson correlation between the number of authorships/paper $(1-10)$ and the percentage of female authorships is $r=.749$ (significant at $p=.013)$. 
TABLE 2

Number and percentage of authorships in Psychology (WoS, 2009) distributed by gender and geographical location and sorted by total number of authorships (of known gender) in descending order

\begin{tabular}{|c|c|c|c|c|c|}
\hline Geographical location & Total (known gender) & Male authorships & $\%$ & Female authorships & $\%$ \\
\hline USA & 35,980 & 19,264 & 53.5 & 16,716 & 46.5 \\
\hline European Union ${ }^{\mathrm{a}}$ & 24,127 & 13,790 & 57.2 & 10,337 & 42.8 \\
\hline United Kingdom & 6280 & 3539 & 56.4 & 2741 & 43.6 \\
\hline Germany & 4726 & 3001 & 63.5 & 1725 & 36.5 \\
\hline Canada & 4406 & 2293 & 52.0 & 2113 & 48.0 \\
\hline Netherlands & 3205 & 1874 & 58.5 & 1331 & 41.5 \\
\hline Australia & 2866 & 1459 & 50.9 & 1407 & 49.1 \\
\hline Spain & 2566 & 1412 & 55.0 & 1154 & 45.0 \\
\hline Italy & 1529 & 721 & 47.2 & 808 & 52.8 \\
\hline France & 1500 & 809 & 53.9 & 691 & 46.1 \\
\hline Belgium & 1036 & 677 & 65.3 & 359 & 34.7 \\
\hline Switzerland & 1006 & 645 & 64.1 & 361 & 35.9 \\
\hline Japan & 793 & 557 & 70.2 & 236 & 29.8 \\
\hline Sweden & 726 & 419 & 57.7 & 307 & 42.3 \\
\hline Israel & 689 & 351 & 50.9 & 338 & 49.1 \\
\hline Brazil & 610 & 268 & 43.9 & 342 & 56.1 \\
\hline Finland & 600 & 265 & 44.2 & 335 & 55.8 \\
\hline Peoples R China & 473 & 299 & 63.2 & 174 & 36.8 \\
\hline Norway & 473 & 294 & 62.2 & 179 & 37.8 \\
\hline New Zealand & 468 & 261 & 55.8 & 207 & 44.2 \\
\hline Austria & 365 & 211 & 57.8 & 154 & 42.2 \\
\hline Turkey & 348 & 150 & 43.1 & 198 & 56.9 \\
\hline Portugal & 303 & 158 & 52.1 & 145 & 47.9 \\
\hline South Africa & 281 & 140 & 49.8 & 141 & 50.2 \\
\hline Others & 3184 & 1715 & 53.9 & 1469 & 46.13 \\
\hline
\end{tabular}

${ }^{a}$ Data obtained by adding the data from all the countries of the European Union (EU-28), including the European countries contained in the others category.

TABLE 3

Number of male and female authorships in Psychology (WoS, 2009) distributed by the number of authorships per article

\begin{tabular}{lcccc}
\hline $\begin{array}{l}\text { Authorships/ } \\
\text { article }\end{array}$ & Male authorships & $\%$ & Female authorships & $\%$ \\
\hline 1 & 2125 & 64.1 & 1191 & 35.9 \\
2 & 6672 & 56.0 & 5244 & 44.0 \\
3 & 8706 & 54.6 & 7233 & 45.4 \\
4 & 7485 & 54.8 & 6182 & 45.2 \\
5 & 5263 & 54.2 & 4456 & 45.8 \\
6 & 3516 & 53.6 & 3038 & 46.4 \\
7 & 2333 & 53.4 & 2038 & 46.6 \\
8 & 1647 & 54.2 & 1390 & 45.8 \\
9 & 981 & 51.9 & 908 & 48.1 \\
10 & 597 & 52.5 & 540 & 47.5 \\
$>10$ & 1457 & 50.8 & 1411 & 49.2 \\
\hline
\end{tabular}

Another issue examined in this study was the collaboration pattern at both national and international levels. There were 22,466 national articles signed by 54,895 authorships, yielding an average of 2.44 authorships per paper. The number of international articles was much smaller, although the level of collaboration was somewhat higher: a total of 4652 articles were signed by 16,006 authorships, resulting in an average of 3.44 authorships per paper.
Within the subset of national articles, the percentages of male and female authorships were $53.1 \%(29,144$ authorships) and $46.9 \%$ (25,751 authorships), respectively. Within the subset of international papers, the percentages of male and female authorships were $58.8 \%$ (9404 authorships) and 41.2\% (6602 authorships), respectively. This relative difference was significant, $\chi^{2}(1)=160.17 ; p<.001$, Cramer's $V=.048$ (small effect size); that is, female participation is slightly lower (although significant) in the publications resulting from international collaboration than in the publications resulting from national collaboration.

We examined the author order in the by-line of each paper. Following the procedure introduced by Kretschmer, Kundra, Beaver, and Kretschmer (2012), the concentrations of females (COF) and males (COM) in each position of the by-line were calculated. After excluding the single-author papers, the COF in each position was defined as the ratio between the percentage of females in that specific position and the overall percentage of female authorships. In the same way, the $\mathrm{COM}$ in each position was defined as the ratio between the percentage of males in that specific position and the overall percentage of male authorships. Figure 1 displays the results. In relative terms, women are overrepresented in the first position $(\mathrm{COF}=1.1)$, and are clearly underrepresented in the last position $(\mathrm{COF}=0.86)$. 


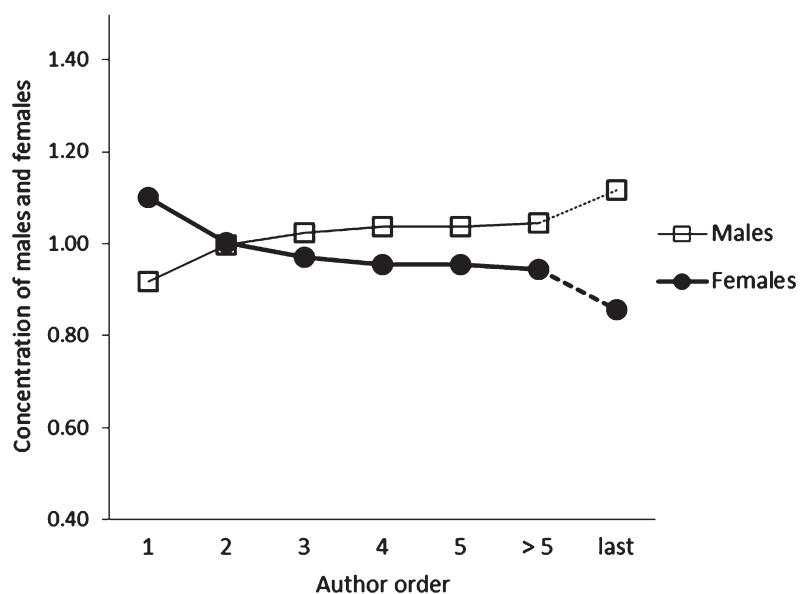

Figure 1. Concentration values of males and females as a function of author order in the by-line of each article of Psychology (WoS, 2009; single-author papers excluded).

Furthermore, we found that the collaborative pattern was different depending on which gender occupied the first and last positions in the paper by-line (see Figure 2). Within the set of multi-authored papers signed by a man in the first position, the number of male and female authorships was $23,128(72.4 \%)$ and $8804(27.6 \%)$, respectively. This percentage difference was significantly more asymmetrical than the overall proportion $(54.8,45.2 \%)$, $\chi^{2}(1)=4006.44 ; p<.0001$. However, if the papers were signed by a woman in the first position, the male authorships $(11,473 ; 35.8 \%)$ were outweighed by the female authorships $(20,589 ; 64.2 \%), \chi^{2}(1)=4676.62 ; p<.0001$. In a similar way, within the set of multi-authored papers signed by a man in the last position, the number of male and female authorships was 27,065 (68.4\%) and $12,513(31.6 \%)$, respectively, which is significantly different from the overall percentages, $\chi^{2}(1)=2948.40$; $p<.0001$. Again, if the papers were signed by a woman in the last position, the male authorships $(7664 ; 31.6 \%)$ were outweighed by the female authorships $(16,585 ; 68.4 \%)$, $\chi^{2}(1)=5266.81 ; p<.0001$. It seems that senior female researchers tend to establish scientific partnerships with women more than male senior researchers do; or perhaps they work on psychological subtopics that are relatively more appealing to women. Conversely, an analogous pattern appears for senior male researchers.

\section{Content}

Revisiting Table 1, we can see the Web of Science Categories (WC) sorted by female-authorship percentages in descending order. The Developmental Psychology (57.0\%) and Educational Psychology (53.8\%) categories show a higher proportion of female researchers than male researchers. It seems that the scientific study of human development and human learning are attractive subjects

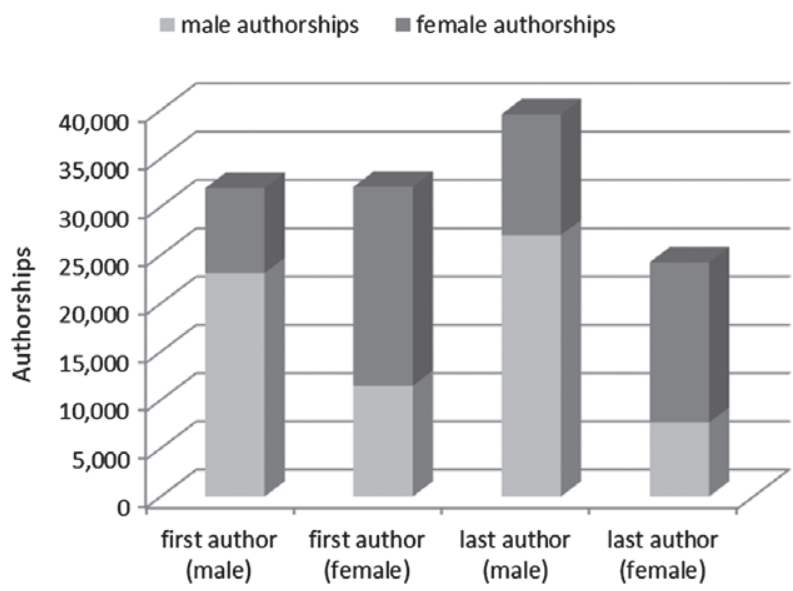

Figure 2. Number of male and female authorships depending on which gender occupied the first and last positions in the paper by-line (single-author papers excluded).

for women. Both categories are followed by Clinical Psychology, with $46.5 \%$ female authorships. At the other extreme, Mathematical Psychology shows only $25.8 \%$ of female participation followed by Experimental Psychology (37.5\%), Applied Psychology (38.8\%) and Biological Psychology (39.4\%).

In order to perform a more fine-grained analysis of the scientific content of our sample, we used the keywords for each article. In addition to the keywords proposed by the authors themselves, Thomson Reuters has included a new field in recent years (Keywords Plus, ID field), providing additional keywords to expand the search in the database (see Zhang et al., 2016, for a comparative study). Table S1 presents the top $30 \%$ of Keywords Plus from the papers separated by the gender of the authors occupying a key (first or last) position in the authorship by-line. Examining the overall set, a close correspondence between the terms in the two columns ("male" and "female" columns) is evident. For example, in both genders the top 5\% corresponded to keywords such as behaviour, performance, children, model, perception, depression or adolescents. However, within the female column, two new terms were included in the top 5\%: women and health. By contrast, the terms information, personality and memory only were included in the top 5\% of the male column. Overall, the terms occupying a higher position in the female column (bold in Table S1) were: adjustment, gender, predictors, adults, childhood, gender-differences, language, young-children, sex-differences, social support, acquisition, quality-of-life, life and patterns. The terms occupying a higher position in the male column (underlined in Table S1) were more numerous, and the most informative are: individual-differences, working-memory, anxiety, brain, activation, disorder, work, major-depression, decision-making, psychotherapy, judgments, emotion, time and schizophrenia. 


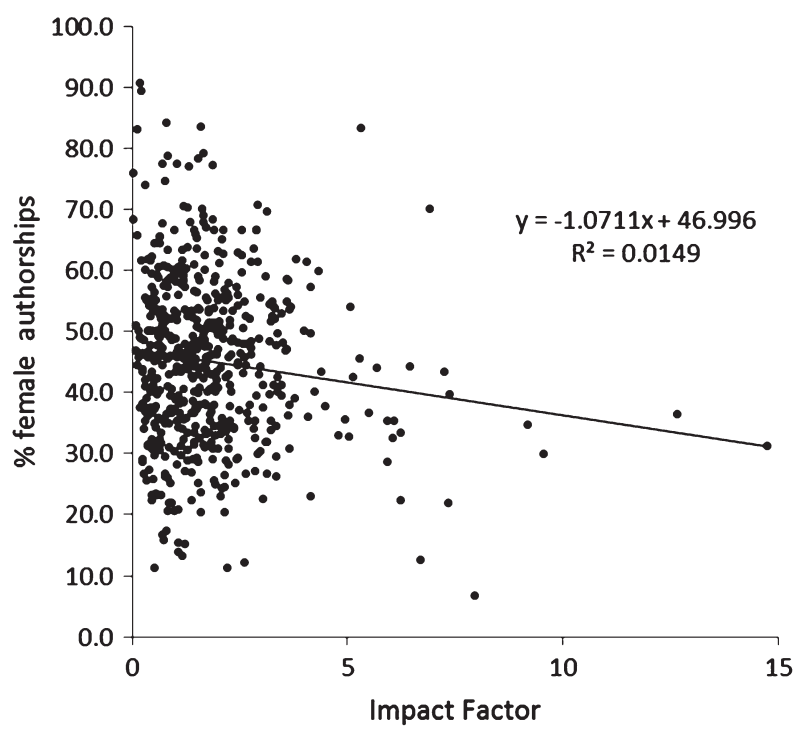

Figure 3. Regression plot of percentages of female authorship as a function of the impact factor (JCR, 2014) of 559 Psychology journals (WoS, 2009).

\section{Scientific impact}

The 27,157 articles in our sample were published in 582 journals, of which 559 were included in the 2014 Journal Citations Reports (JCR, 2014). For each journal, we calculated the percentage of female authorships and obtained the impact factor (2-years; IF) from JCR-2014. Figure 3 displays the regression plot of percentages of female authorship as a function of the impact factor of the 559 journals. The Pearson correlation is negative, small in absolute terms but significant $(r=-0.122 ; p=.004)$, mainly because the journals with higher IF present a lower proportion of female authorships, such as Psychological Bulletin (IF $=14.756 ; 31.3 \%)$, Annual Review of Clinical Psychology ( IF $=14.756 ; 36.4 \%)$, Perspectives on Psychological Science $(\mathrm{IF}=9.546 ; 29.9 \%)$, Psychotherapy and Psychosomatics $(\mathrm{IF}=9.196 ; 34.6 \%)$, Psychological Review (IF $=7.972 ; 6.7 \%$ ) or Social Cognitive and Affective Neuroscience $(\mathrm{IF}=7.372 ; 39.8 \%)$.

The scientific impact was also assessed through the number of citations that each paper received (TC, Times Cited). These data were extracted and subsequently assigned to every authorship of each paper; then, the citations were averaged for each individual (author) and separated by gender (males, females) in order to perform a between-subjects one-way ANOVA. Overall, men received 16.57 cites/author $(S D=20.19)$, 95\% CI [16.32, 16.80], and women received 15.90 cites/authorship $(S D=18.04), 95 \%$ [16.67, 16.14]. Given the number of observations, this citation difference (0.67) was significant, although the effect size was very small, $F(1,49,028)=14.48, M S E=366.5, p<.0001$, $\eta_{\mathrm{p}}^{2}<.001$.

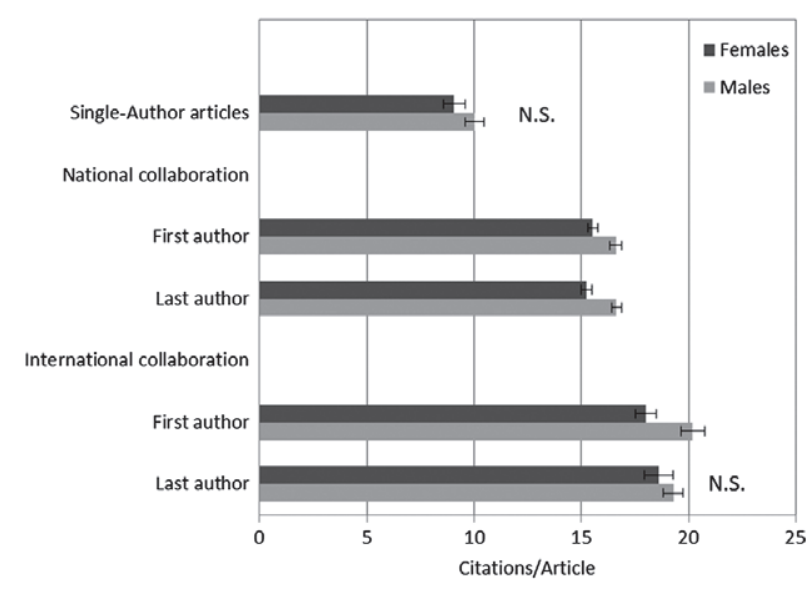

Figure 4. Averages of number of citations received by Psychology articles with males and females in key positions of the by-line (single author, first author, last author). Multi-authored articles are separated between those resulting from national or international collaborations. Error bars indicate \pm one standard error of the mean. N.S.: gender difference in citations non-significant.

Figure 4 displays the citation averages for Psychology articles with men and women in key positions of the by-line: single author, first author (of multi-authored articles) and last author (of multi-authored articles). The first point worth noting is that single-author articles written by a man or a woman received a similar number of citations: 10.02 versus 9.07 citations, respectively; a one-way ANOVA yielded no statistically significant differences between genders, $F(1,3314)=1.86$, $M S E=369.5, p=.172$. In a similar way to Larivière et al. (2013), we distinguished between multi-authored papers resulting from national versus international collaborations (see above). As expected, articles resulting from international collaborations were more visible and globally received more citations (18.94) than those resulting from national collaborations (15.72). Within the set of national-collaboration papers, those in which a female occupied the first or last position of the by-line were cited slightly less than articles in which a male occupied these positions. Data for the first author position were: 16.61 versus 15.54 citations for articles signed, respectively, by males versus females in that position; this difference was significant (after Bonferroni correction for multiple comparisons) but very small in terms of effect size, $F(1,15,379)=9.57, M S E=462.7, p=.0038, \eta^{2}{ }_{p}=.002$. Data for the last author position in the by-line were: 16.65 versus 15.23 citations for articles signed, respectively, by males versus females in that position, $F(1$, $15,523)=16.51, \quad M S E=452.5, \quad p<.0001, \quad \eta^{2}=.001$; again, this difference was significant but quite small in terms of effect size.

Within the set of international-collaboration articles, the gender difference was only significant for the first position of the by-line. Data for the first position were: 
20.21 versus 18.01 citations for articles signed, respectively, by males versus females in that position; this difference was significant (after Bonferroni correction), but very small in terms of effect size, $F(1,3740)=8.30$, $M S E=538.2, p=.0078, \eta^{2}=.002$. Data for the last position were: 19.29 versus 18.61 citations for articles signed, respectively, by males versus females in that position; this difference was not significant, $F(1,3833)=0.69$, $M S E=559.5, p=.407$.

\section{DISCUSSION}

We carried out a gender analysis of all the Psychology articles published in 2009 included in the WoS, and we found that $54.8 \%$ of the authorships were men and $45.2 \%$ were women. These percentages corresponded to $49.9 \%$ individual male authors and $50.1 \%$ female authors. This gender balance in the number of authors (and almost in the number of authorships) does not exist in overall science and other specific fields. The last UNESCO Science Report (UNESCO, 2015) stated that only $28 \%$ of worldwide researchers are women. Larivière et al. (2013) analysed more than 5 million scientific articles and found that women accounted for fewer than $30 \%$ of authorships. West et al. (2013) examined 1.8 million science and humanities papers and obtained an overall $21.9 \%$ of female authorships.

The gender proportion varies across different fields. Data from Larivière et al. (2013) confirmed previous findings and anecdotal observations that fields associated with "care" (health, education) present less gender disparity than "hard" sciences (computer sciences, high-energy physics, etc.). Sotudeh and Khoshian (2014) observed that research by women in Nano Science \& Technology during 2005-2007 only accounted for $11.98 \%$ of all papers. Cavero et al. (2015) analysed women participation in Computing research since its beginnings, and they obtained a growth from only $<3 \%$ of all publications in 1966 , to $16.3 \%$ in 2010 . In Software Engineering, Vela et al. (2012) found that only $17.2 \%$ of authors were female. In the medical field, women representations have increased in recent decades. However, after analysing authorships in six prominent medical journals during 1970-2004, Jagsi et al. (2006) concluded that "over the past four decades, the proportion of women among both first and senior physician-authors of original research in the USA has significantly increased. Nevertheless, women still compose a minority of the authors of original research and guest editorials in the journals studied" (p. 281). Recently, the authors (González-Alvarez \& Cervera-Crespo, 2017) obtained $67.1 \%$ of male authorships and $32.9 \%$ of female authorships in high-impact journals of Neuroscience. Table 1 of West et al.'s (2013) showed that female authorships during the 1990-2011 period ranged from $10.64 \%$ in Mathematics, $12.04 \%$ in
Philosophy, $13.68 \%$ in Economics, and so on to $41.41 \%$ in Sociology, $41.90 \%$ in Demography and $46.35 \%$ in Education. It is worth noting that our averages of $54.8 \%$ male authorships and $45.2 \%$ female authorships (49.9\% individual men and $50.1 \%$ individual women) display a relatively balanced frame in the case of the Psychology articles published in 2009 .

The pattern of collaboration was examined analysing the author order in the by-line of the multi-author articles and its gender composition. Our data showed that women tend to be overrepresented in the first position and, at the same time, clearly underrepresented in the last one (Figure 1). The first observation could be a reflection of new female incorporations into psychological research who are publishing their first studies under the direction of a senior researcher (last position in the by-line). Regarding the second observation, it should be said that in many scientific fields, including health and behavioural sciences, the last author position of a paper is a key position frequently reserved for the senior or leading member of the research team (West et al., 2013). In other fields, such as mathematics or economics, for instance, the author order is usually alphabetical (Waltman, 2012; West et al., 2013). This double pattern - relative overrepresentation of women in the first position and relative underrepresentation in the last position of authorships - also found in other fields (Larivière et al., 2013), could suggest that age probably plays a role in psychology.

Age probably plays a role in the number of citations received. When the citations are averaged for each individual (author), the overall difference between men and women is less than one citation. Furthermore, the citations received by single-author articles signed by a man versus a woman are comparable (not significantly different). However, the asymmetry increases when considering the national/international status of papers and the greatest imbalance is linked to the gender composition of the first and the last (senior) position. Presumably, researchers with a larger career have had the opportunity to establish more scientific/academic contacts and gain greater visibility.

In summary, our data from the psychological field shows a slight gender imbalance in the number of authorships and a gender parity in the number of individual authors. In comparative terms, this relative balance is not found in science in general (less than one third are by female researchers). Nevertheless, some caution should be exercised when generalising these results beyond the sample obtained from the WoS. Using more comprehensive databases with respect to psychology journals (such as PsycINFO, Google Scholar, or Scopus, which at the moment are unable to automatically provide the authors' full names of a set of records), the women representation probably turns out to be even larger. In any case, the great disproportion between the number of female undergraduate's students and the number of female researchers in 
psychological areas indicates that the phenomenon known as "leaky pipeline" of women in science (Shen, 2013; UNESCO, 2015) is also present in the contemporary psychology. As mentioned above, one of reasons for a relative asymmetry in the number authorships probably has to do with age (fewer senior female researchers in relative terms), and part of the gender imbalance will be corrected in the coming years, but surely other forces - differential investment in family and childcare, subtle gender bias, and so forth-continue to act in the opposite direction. It is the society's responsibility to combat such forces in the near future (see p.e., Nature, 2013; Shen, 2013).

Manuscript received November 2016 Revised manuscript accepted April 2017

\section{SUPPORTING INFORMATION}

Additional Supporting Information may be found in the online version of this article:

Appendix S1. Method.

Table S1. Top 30\% of Keywords Plus extracted from the articles published on Psychology (WoS, 2009) and separated by authorship gender (first or last position in the by-line). Keywords in bold rise one or more steps when going from male to female authorships. Underlined keywords descend one or more steps when going from male to female authorships.

\section{REFERENCES}

Barrios, M., Villarroya, A., \& Borrego, A. (2013). Scientific production in psychology: A gender analysis. Scientometrics, 95(1), 15-23. https://doi.org/10.1007/s11192-012-0816-4.

Boice, R., Shaughnessy, P., \& Pecker, G. (1985). Women and publishing in psychology. American Psychologist, 40(5), 577. https://doi.org/10.1037/0003-066X.40.5.577.

Carnahan, S., Kryscynski, D., \& Olson, D. (2016). When does corporate social responsibility reduce employee turnover? Evidence from attorneys before and after 9/11. Journal of Academy of Management. https://doi.org/10.5465/amj.2015 .0032 .

Cavero, J. M., Vela, B., Cáceres, P., Cuesta, C., \& Sierra-Alonso, A. (2015). The evolution of female authorship in computing research. Scientometrics, 103(1), 85-100. https://doi.org/10 .1007/s11192-014-1520-3.

Cohen, J. (1988). Statistical power analysis of the behavioral sciences (2nd ed.). New York, NY: Academic Press.

Cumming, G., Siddle, D., \& Hyslop, W. (1997). Psychological science in Australia. International Journal of Psychology, 32(6), 409-424. https://doi.org/10.1080/002075997400656.

D’Amico, R., Vermigli, P., \& Canetto, S. S. (2011). Publication productivity and career advancement by female and male psychology faculty: The case of Italy. Journal of Diversity in Higher Education, 4(3), 175. https://doi.org/10.1037/ a0022570.

González-Alvarez, J., \& Cervera-Crespo, T. (2017). Research production in high-impact journals of contemporary neuroscience: A gender analysis. Journal of Informetrics, 11(1), 232-243. https://doi.org/10.1016/j.joi.2016.12 .007 .

González-Alvarez, J., \& Palomar-García, M. (2014). Twenty-two years of psychological science in Psychological Science. International Journal of Psychology, 49(1), 56-60. https://doi.org/10.1002/ijop.12009.

Gravetter, F. J., \& Wallnau, L. B. (2012). Statistics for the behavioral sciences (9th ed.). Belmont, CA: Wadsworth Publishing Company.

Guyer, L., \& Fidell, L. (1973). Publications of men and women psychologists: Do women publish less? American Psychologist, 28(2), 157. https://doi.org/10.1037/h0034240.

Jagsi, R., Guancial, E. A., Worobey, C. C., Henault, L. E., Chang, Y., Starr, R., ... Hylek, E. M. (2006). The "gender gap" in authorship of academic medical literature-A 35-year perspective. The New England Journal of Medicine, 355(3), 281-287. https://doi.org/10.1056/NEJMsa053910.

JCR (2014). Journal Citation Reports (JCR) Edition 2014. Thomson Reuters.

Kliegl, R., \& Bates, D. (2011). International collaboration in psychology is on the rise. Scientometrics, 87(1), 149-158. https://doi.org/10.1007/s11192-010-0299-0.

Kretschmer, H., Kundra, R., Beaver, D., \& Kretschmer, T. (2012). Gender bias in journals of gender studies. Scientometrics, 93(1), 135-150. https://doi.org/10.1007/s11192012-0661-5.

Larivière, V., Ni, C., Gingras, Y., Cronin, B., \& Sugimoto, C. R. (2013). Bibliometrics: Global gender disparities in science. Nature, 504(7479), 211-213. https://doi.org/10.1038/ 504211a.

Malouff, J., Schutte, N., \& Priest, J. (2010). Publication rates of Australian academic psychologists. Australian Psychologist, 45(2), 78-83. https://doi.org/10.1080/00050060903078536.

Mansour, A. M., Shields, C. L., Maalouf, F. C., Massoud, V. A., Jurdy, L., Mathysen, D. G., ... Aclimandos, W. (2012). Five-decade profile of women in leadership positions at ophthalmic publications. Archives of Ophthalmology, 130(11), 1441-1446. https://doi.org/10.1001/archophthalmol.2012 .2300 .

Mauleón, E., \& Bordon, M. (2006). Productivity, impact and publication habits by gender in the area of Materials Science. Scientometrics, 66(1), 199-218. https://doi.org/10.1007/ s11192-006-0014-3.

Nature (2013). Science for all [Editorial]. Nature, 495, 5. https:// doi.org/10.1038/495005a.

Persson, O. D., Danell, R., \& Wiborg-Schneider, J. (2009). How to use Bibexcel for various types of bibliometric analysis. In F. Astrom, R. Danell, B. Larsen, \& J. Schneider (Eds.), Celebrating scholarly communication studies: A Festschrift for Olle Persson at his 60th Birthday (pp. 9-24). Leuven, Belgium: International Society for Scientometrics and Informetrics. Retrieved from http://www8. umu.se/inforsk/Bibexcel/

Quayle, M., \& Greer, M. (2014). Mapping the state of the field of social psychology in Africa and patterns of collaboration between African and international social psychologists. International Journal of Psychology, 49(6), 498-502. https://doi.org/10.1002/ijop.12059.

Shen, H. (2013). Inequality quantified: Mind the gender gap. Nature, 495(7439), 22-24. https://doi.org/10.1038/495022a. 
Sotudeh, H., \& Khoshian, N. (2014). Gender differences in science: The case of scientific productivity in Nano Science \& Technology during 2005-2007. Scientometrics, 98(1), 457-472. https://doi.org/10.1007/s11192-013-1031-7.

UNESCO. (2015). United Nations Educational, Scientific and Cultural Organization. UNESCO Science Report Towards 2030.

Vela, B., Cáceres, P., \& Cavero, J. M. (2012). Participation of women in software engineering publications. Scientometrics, 93(3), 661-669. https://doi.org/10.1007/s11192-012-0774$\mathrm{x}$.

Waltman, L. (2012). An empirical analysis of the use of alphabetical authorship in scientific publishing. Journal of Informetrics, 6(4), 700-711. https://doi.org/10.1016/j.joi.2012 .07 .008 .
West, J. D., Jacquet, J., King, M. M., Correll, S. J., \& Bergstrom, C. T. (2013). The role of gender in scholarly authorship. PLoS One, 8(7), e66212. https://doi.org/10.1371/journal .pone.0066212.

Yun, E. J., Yoon, D. Y., Kim, B., Moon, J. Y., Yoon, S. J., Hong, S. J., \& Baek, S. (2015). Closing the gender gap: Increased female authorship in AJR and Radiology. American Journal of Roentgenology, 205(2), 237-241. https://doi.org/10.2214/ AJR.14.14225.

Zhang, J., Yu, Q., Zheng, F., Long, C., Lu, Z., \& Duan, Z. (2016). Comparing keywords plus of WOS and author keywords: A case study of patient adherence research. Journal of the Association for Information Science and Technology, 67, 967-972. https://doi.org/10.1002/asi.23437. 